\title{
Cancer-derived immunoglobulin G promotes tumor cell growth and proliferation through inducing production of reactive oxygen species
}

\author{
J Wang ${ }^{1,2}$, D Lin ${ }^{1,2}$, H Peng ${ }^{1}$, Y Huang ${ }^{1}$, J Huang ${ }^{1}$ and J Gu ${ }^{*, 1}$
}

Cancer cells have been found to express immunoglobulin $G(\mathrm{lg} G)$, but the exact functions and underlying mechanisms of cancerderived IgG remain elusive. In this study, we first confirmed that downregulation of IgG restrained the growth and proliferation of cancer cells in vitro and in vivo. To elucidate its mechanism, we carried out a co-immunoprecipitation assay in HeLa cells and identified 27 potential IgG-interacting proteins. Among them, receptor of activated protein kinase C 1 (RACK1), ras-related nuclear protein (RAN) and peroxiredoxin 1 (PRDX1) are closely related to cell growth and oxidative stress, which prompted us to investigate the mechanism of action of IgG in the above phenomena. Upon confirmation of the interactions between IgG and the three proteins, further experiments revealed that downregulation of cancer-derived IgG lowered levels of intracellular reactive oxygen species (ROS) by enhancing cellular total antioxidant capacity. In addition, a few ROS scavengers, including catalase (CAT), dimethylsulfoxide (DMSO), n-acetylcysteine (NAC) and superoxide dismutase (SOD), further inhibited the growth of IgG-deficient cancer cells through suppressing mitogen-activated protein kinase/extracellular-regulated kinase (MAPK/ERK) signaling pathway induced by a low level of intracellular ROS, whereas exogenous hydrogen peroxide $\left(\mathrm{H}_{2} \mathrm{O}_{2}\right)$ at low concentration promoted their survival via increasing intracellular ROS levels. Similar results were obtained in an animal model and human tissues. Taken together, our results demonstrate that cancer-derived IgG can enhance the growth and proliferation of cancer cells via inducing the production of ROS at low level. These findings provide new clues for understanding tumor proliferation and designing cancer therapy.

Cell Death and Disease (2013) 4, e945; doi:10.1038/cddis.2013.474; published online 5 December 2013

Subject Category: Cancer

The classic concept that immunoglobulins were produced only by $B$ lymphocytes and plasma cells was challenged when many non-lymphoid lineage cells were found to have the ability to produce IgG. These include cancer cells such as breast cancer cells, ${ }^{1-3}$ colorectal cancer cells, ${ }^{4,5}$ prostate cancers cells, ${ }^{6}$ papillary thyroid cancer cells ${ }^{7}$ and soft tissue tumors, ${ }^{8}$ human umbilical endothelial cells, ${ }^{9}$ testicular spermatogenic cells, ${ }^{10}$ epididymal epithelial cells, ${ }^{10}$ human and mouse neurons ${ }^{11,12}$ and eyes. ${ }^{13}$ It was reported that IgG secreted by human cancers promoted growth and survival of tumor cells. ${ }^{1}$ IgG detected in a wide variety of neoplasms was found to correlate with proliferation markers and tumor grades. ${ }^{1,3,5}$ Furthermore, knockdown of the expression of heavy-chain genes of immunoglobulin isotypes through siRNA suppressed cancer cell growth in vitro and in vivo. ${ }^{14}$
However, the regulatory mechanism of the above biological effects remains uncertain.

In this study, we designed and performed a series of experiments to investigate the cellular mechanism of cancerderived $\lg \mathrm{G}$. We found that downregulation of $\lg G$ with siRNA silencing inhibited the growth and proliferation of a variety of cancer cell types in vitro and in vivo. Subsequently, we performed a co-immunoprecipitation coupled liquid chromatography-tandem mass spectrometry (LC-MS/MS) analysis to identify potential IgG-interacting proteins. Among the 27 candidate IgG-binding proteins obtained, guanine nucleotide binding protein ( $G$ protein), beta polypeptide 2-like 1 (GNB2L1; RACK1) and RAN were involved in cellular growth, and PRDX1, an antioxidase, participated in cellular antioxidate and proliferation. The above three proteins are

\footnotetext{
${ }^{1}$ Provincial Key Laboratory of Infectious Diseases and Molecular Immunopathology, Department of Pathology, Shantou University Medical College, Shantou, China *Corresponding author: J Gu, Department of Pathology, Shantou University Medical College, Shantou 515041, China. Tel: +86 75488900207 ; Fax: + 86754 88950293; E-mail: jguemailbox@gmail.com

${ }^{2}$ These authors contributed equally to this work.

Keywords: IgG; cancer; growth; ROS; signaling

Abbreviations: IgG, immunoglobulin G; RACK1, receptor of activated protein kinase C 1; RAN, ras-related nuclear protein; PRDX1, peroxiredoxin 1; ROS, reactive oxygen species; CAT, catalase; DMSO, dimethylsulfoxide; NAC, n-acetylcysteine; SOD, superoxide dismutase; MAPK/ERK, mitogen-activated protein kinase/ extracellular-regulated kinase; $\mathrm{H}_{2} \mathrm{O}_{2}$, hydrogen peroxide; LC-MS/MS, liquid chromatography-tandem mass spectrometry; GNB2L1, guanine nucleotide binding protein (G protein), beta polypeptide 2-like 1; ATCC, American Type Culture Collection; RT-qPCR, real-time quantitative reverse transcription PCR; MTS, 5-(3carboxymethoxyphenyl)-2-(4, 5-dimenthylthiazoly)-3-(4-sulfophenyl) tetrazolium, inner salt; SDS-PAGE, sodium dodecyl sulfate polyacrylamide gel electrophoresis; DAVID, Database for Annotation, Visualization, and Integrated Discovery; T-AOC, total antioxidant capacity; DAPI, 4',6-diamidino-2-phenylindole; GR, glutathione reductase; GPx, glutathione peroxidase; GSH, glutathione; $\mathrm{O}_{2}^{-}$, superoxide anion; $\mathrm{OH}$. , hydroxyl free radical; DHE, dihydroethidium; DCFH-DA, dichlorofluorescein diacetate; MDA, malondialdehyde; PCNA, proliferating cell nuclear antigen; RP, ribosomal protein; NF- $\kappa$ B, nuclear factor kappa B; PI3K, phosphatidylinositol-3 kinase; VEGF, vascular endothelial growth factor; TBST, tris-buffered saline containing $0.2-0.4 \%$ Tween-20

Received 18.9.13; revised 25.10.13; accepted 29.10.13; Edited by A Stephanou
} 
more closely connected with cell growth and proliferation, compared with other candidate proteins. After confirmation of the interactions between cancer-derived IgG and the above three proteins, we explored the biological activity of cancer-derived IgG in cellular oxidative stress and proliferation.

\section{Results}

Reduction of cancer-derived IgG inhibits cell growth in vitro and in vivo. First, we established IgG expression in a number of cancer cell lines including HeLa, HEp-2 and PC3 and cervical carcinoma tissues (Supplementary Figure S1). In order to verify the identities of the above cell lines, short tandem repeat identifications of HeLa, HEp-2 and PC3 cell lines were performed and the profiles showed $100 \%$ confirmation with those provided by the American Type Culture Collection (ATCC) (Supplementary Figures S2a-c). Then, HeLa cells were transfected with IGHG1 siRNA or scrambled siRNA. Immunoblotting and real-time quantitative reverse transcription PCR (RT-qPCR) were performed to detect the expression of $\lg G \gamma$. The results showed that downregulation of cancer-derived IgG markedly reduced the expression of $\lg \mathrm{g} \gamma$ at both the protein and mRNA


a

SIRNA: CTL IgG

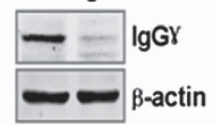

e

SIRNA: CTL IgG

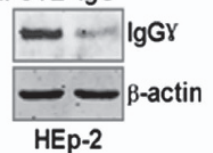

SIRNA: CTL IgG

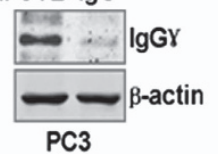

f

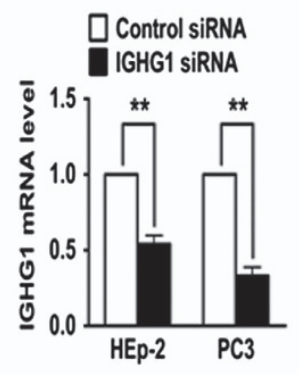

g



C

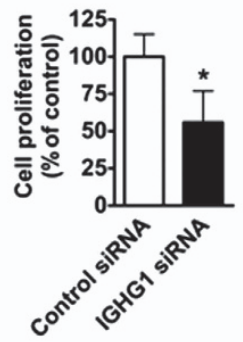

d



i Control siRnA

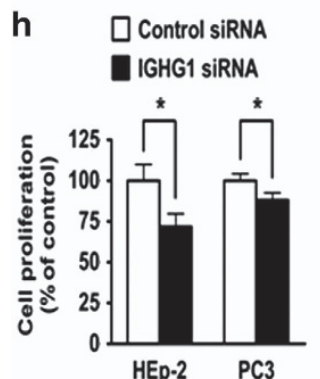





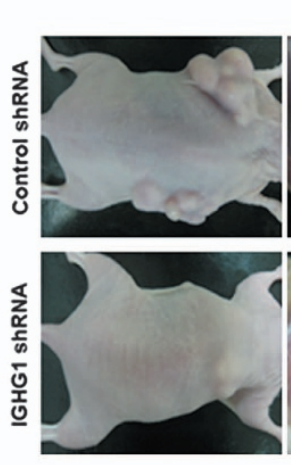

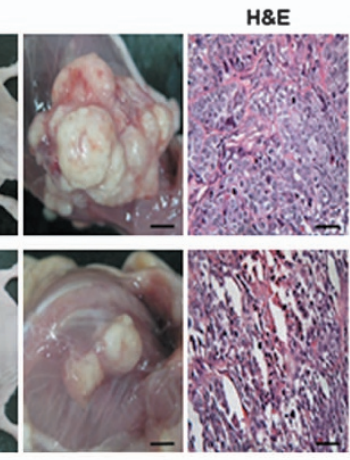

ShRNA: CTL IGG


Figure 1 Knockdown of cancer-derived IgG inhibited the growth and proliferation of cells in vitro and in vivo. HeLa cells were treated with IGHG1 siRNA or scrambled siRNA. IgG $\gamma$ protein levels (a) and mRNA levels (b) were detected. (c) The viability of similarly treated cells was analyzed with cell proliferation assay. Results are presented as percentage of cells proliferation in comparison to the negative control. HEp-2 and PC3 cells were also treated with the same protocol (e, f, h). (d) HeLa cells treated with IGHG1 siRNA or scrambled siRNA were analyzed morphologically 3 days before and 3 days after the treatment. The images are shown in the left panel. Scale bar, $50 \mu \mathrm{m}$. The statistical analysis of cell number under the same conditions was performed and results showed in the right panel. Similar experiments were also performed in HeLa cells stably expressing IGHG1 shRNA or control shRNA (Supplementary Figures S3b-e). (g) Reduced tumor volumes in the bilateral groin of BALB/c nude mice injected with IGHG1 shRNA cells, compared with controls (control shRNA cells). Each data point is the mean value ( \pm S.E.M.) of six tumors. Photographs of representative mice and tumors are shown, along with haematoxylin and eosin staining of tumor. Scale bar, $20 \mu \mathrm{m}$. Western blot and RT-qPCR confirmed tumor originated from injected IGHG1 shRNA cells or control shRNA cells. (i) Reduction of cancer-derived IgG induced cell cycle arrest. HeLa cells were treated with scrambled siRNA or IGHG1 siRNA for $72 \mathrm{~h}$. The cell cycle progression was detected with flow cytometry. The percentage of cells in the S phase was calculated. The RT-qPCR, MTS, cell number and cell cycle data are expressed as mean \pm S.D. from three independent experiments $\left({ }^{*} P<0.05 ;{ }^{* *} P<0.01\right)$ 
levels (Figures 1a and $b$ and Supplementary Figure S3a). 5-(3-carboxymethoxyphenyl)-2-(4, 5-dimenthylthiazoly)-3(4-sulfophenyl) tetrazolium, inner salt (MTS) assay analysis further demonstrated that siRNA-induced repression of IgG significantly inhibited cell growth and proliferation (Figure 1c). Similar results were obtained with HEp-2 and PC3 cells (Figures 1e, f and h).

HeLa cells treated with IGHG1 siRNA or scrambled siRNA were analyzed marphotogically 3 days before and 3 days after the treatment. It was found that the number of deficient cells was significantly less than that of cells treated with scrambled siRNA 3 days after the treatment (Figure 1d, right panel). Flow cytometry assay revealed a significant reduction of cell population in the S phase after IgG knockdown in HeLa cells with siRNA (Figure 1i). Similar results were obtained in HeLa cell lines stably expressing IGHG1 shRNA or control shRNA (Supplementary Figures S3b-f). We tested whether IGHG1 reduction from HeLa cells inhibits tumor growth. We injected subcutaneously control shRNA and IGHG1 shRNA1 cells into $\mathrm{BALB} / \mathrm{c}$ nude mice. In contrast to control shRNA cells, which formed large tumors within 43 days (6 out of 6 mice), all six mice injected with IGHG1 shRNA cells led to greatly reduced tumor growth (Figure 1g).

Identification and functional classification of cancerderived IgG-interacting proteins. We then screened potential cancer-derived IgG-interacting proteins with co-immunoprecipitation combined with LC-MS/MS. HeLa cell lysate was immunoprecipitated with mouse antihuman IgG $\gamma$ antibody and normal mouse IgG. The immunocomplex was run in sodium dodecyl sulfate polyacrylamide gel electrophoresis (SDS-PAGE) and detected with silver staining.

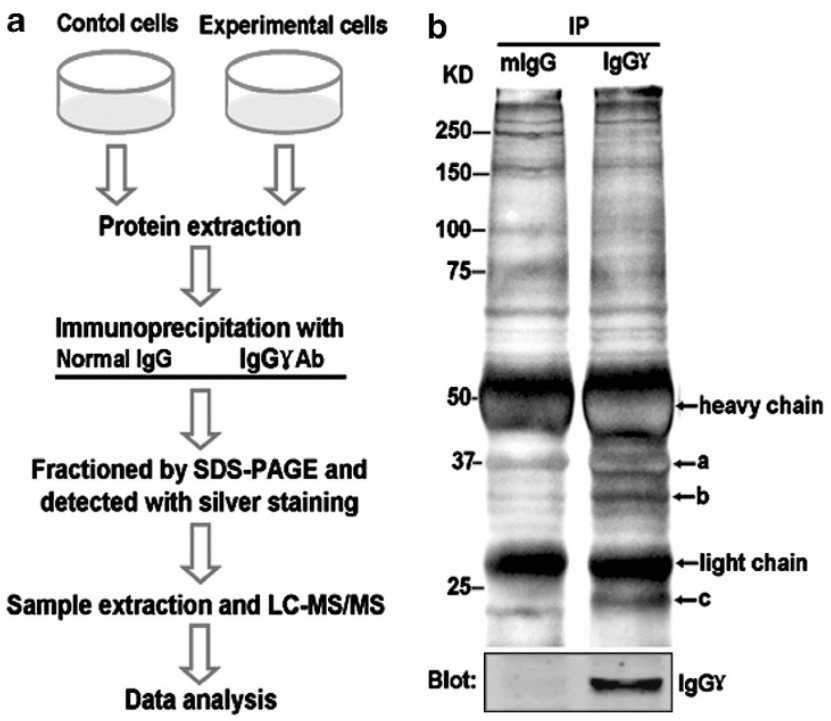

Figure 2 Identification of cancer-derived IgG-associated proteins. (a) Schematic illustration of the strategy used to screen cancer-derived IgG-associated proteins. (b) Proteins immunoprecipitated with mouse anti-human IgG ( $\gamma$ chainspecific) antibody or normal mouse IgG from total lysates of HeLa cells were fractionated with 10\% SDS-PAGE gel. The gels were either visualized with silver staining (upper panel) or blotted with anti-lgG $\gamma$ antibodies (lower panel). The differential bands (marked a-c) were subjected to trypsin digestion and LC-MS/MS analysis. The identified proteins were listed along with the corresponding bands (Supplementary Table S1)
Three prominently enhanced bands were subjected to protein identification with LC-MS/MS (Figure $2 \mathrm{~b}$ marked $\mathrm{a}-\mathrm{c})$. The MS data were analyzed with the National Center for Biotechnology Information database. The strategy used to screen cancer-derived IgG-associated proteins is illustrated in Figure 2a. After analyzing the data, we eventually identified 27 putative cancer-derived IgG-associated proteins (Supplementary Table S1).

To understand the functions of these potential IgG binding proteins, we carried out functional annotations with the Database for Annotation, Visualization and Integrated Discovery (DAVID, http://david.abcc.ncifcrf.gov/). The annotation revealed that the proteins were localized in the cytoplasm, the nucleus and the mitochondria and were involved in various biological processes such as cell growth and proliferation, protein synthesis, antioxidants and so on (Supplementary Table S2). Among proteins with the annotated functions, RACK1, RAN and PRDX1 were classified as being involved in cell growth and proliferation. PRDX1 is an antioxidant, participating in cellular oxidative stress. Based on the evidence of IgG involvement in cancer cell growth and oxidative stress, we selected RACK1, RAN and PRDX1 for further investigation.

Cancer-derived IgG interacts with RACK1, RAN and PRDX1 in cell cytoplasm and forms a macro-protein complex. To further verify the interactions between cancerderived IgG and RACK1, RAN and PRDX1, we performed independent precipitations with a mouse anti-human $\lg \mathrm{G} \gamma$ antibody or normal mouse IgG. The results confirmed that the three proteins could bind to endogenous IgG independently (Figure 3a).

In a similar manner, It was found that RAN or PRDX1 could bind to RACK1, and RAN could bind to PRDX1 (Figures 3b and $\mathrm{c}$ ). Confocal immunofluorescence microscopy revealed that IgG colocalized with RACK1, RAN, and PRDX1 well in the cytoplasm of HeLa cells (Figure $3 d$ ), RACK1 colocalized with RAN or PRDX1 well in the cytoplasm, and PRDX1 and RAN were also colocalized well in the cytoplasm (Figure 3e). To test the crossreactivity between anti-human $\operatorname{lgG} \gamma$ and RACK1, RAN, PRDX1 or anti-human RACK1 and RAN, PRDX1 or anti-human RAN and PRDX1, we synthetized RACK1, RAN and PRDX1 peptides with 20 amino acids (Supplementary Figure S4a) as antigens and completed dot-blot immunoassay. The results showed that the above four antibodies didn't identify other three peptides except for its own antigen (Supplementary Figures S4b-e).

Reduction of cancer-derived IgG enhances cellular total antioxidant capacity. To explore the mechanism of cancerderived IgG involving in cellular oxidative stress response, we performed a series of experiments to investigate the possible effect of $\operatorname{lgG}$ on cell total antioxidant capacity including antioxidant enzymes and small molecular antioxidants. It was found that knockdown of IgG markedly enhanced cellular total antioxidant capacity (T-AOC) (Figure 4a) including the expression levels or activities of various antioxidant enzymes and contents of small molecule antioxidants. Immunoblotting and RT-qPCR were performed in HeLa cells to detect the expression of PRDX1 


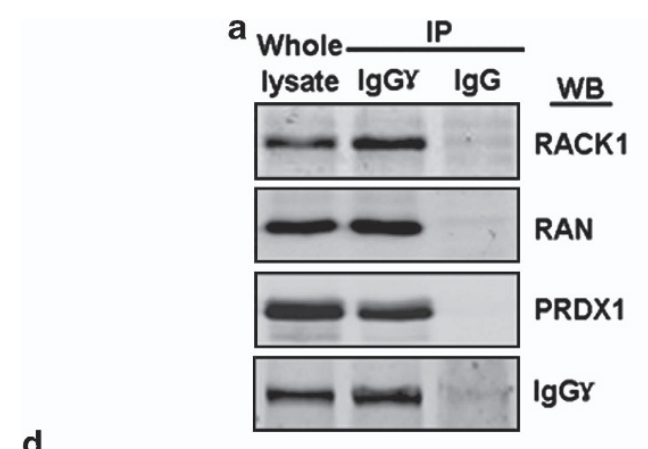

d
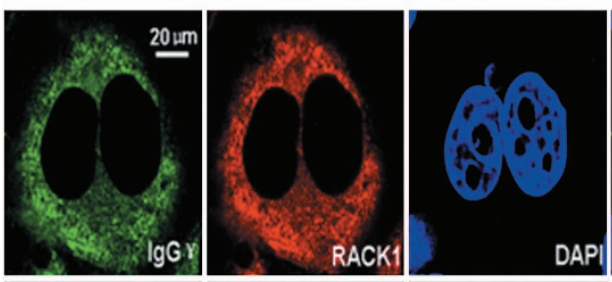

b



e
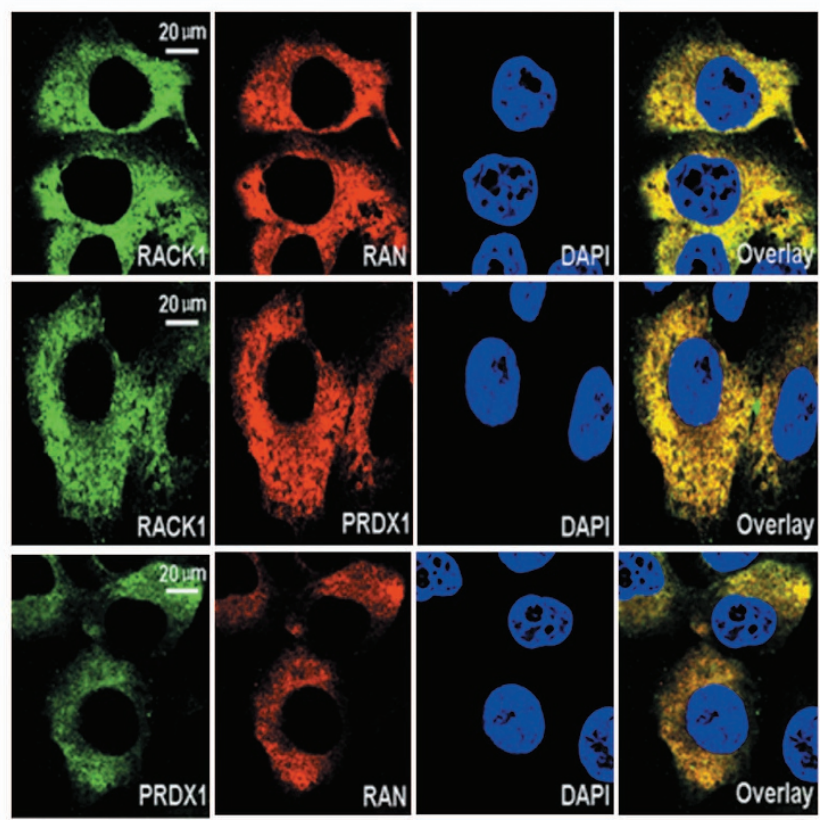

RAN

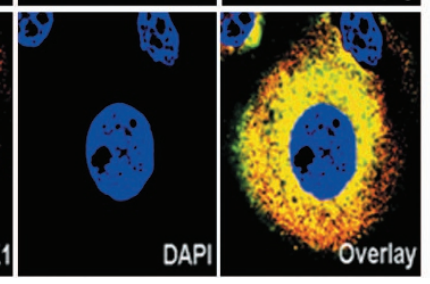

Figure 3 Cancer-derived IgG interacted with RACK1, RAN and PRDX1 in the cytoplasm of HeLa cells. (a) Cell lysates were immunoprecipitated with mouse anti-human IgG $\gamma$ antibody or normal mouse lgG. The immunoprecipitates and whole-cell lysate were fractionated by SDS-PAGE and blotted with anti-RACK1, anti-RAN, anti-PRDX1 and anti-IgG $\gamma$ antibodies. (b) HeLa cell lysates were immunoprecipitated with mouse anti-RACK1 antibody and normal mouse IgG, the immunoprecipitates and whole-cell lysate were fractionated by SDS-PAGE and blotted with anti-RACK1, anti-RAN or anti-PRDX1 antibody. (c) HeLa cell lysates were immunoprecipitated with goat anti-PRDX1 antibody and normal goat lgG, the immunoprecipitates and whole-cell lysate were fractionated by SDS-PAGE and blotted with anti-RAN. (d and e) HeLa cells were fixed and double-stained for IgG $\gamma$, RACK1 or PRDX1 (green) and RACK1, RAN or PRDX1 (red). Nuclei were stained with 4',6-diamidino-2-phenylindole (DAPI). The merged images (overlay, yellow) were viewed with a confocal microscope and shown in the right panel (Scale bar, $20 \mu \mathrm{m}$ )

after knockdown of IgG. Results showed that downregulation of IgG dramatically elevated the expression of PRDX1 at both protein and mRNA levels (Figures $4 c$ and d). Then, the activities of a few key antioxidant enzymes including total SOD, Mn-SOD, CuZn-SOD, CAT, glutathione reductase (GR) and glutathione peroxidase (GPx) were measured. Results showed that the activities of the above antioxidant enzymes in IgG-deficient cells were significantly higher than those of the control cells (Figures $4 \mathrm{e}-\mathrm{j}$, left panel), in good agreement with the results of T-AOC. Similar results were also obtained with the stably transformed cells (Figures $4 \mathrm{e}-\mathrm{j}$, right panel). The data revealed that the content of glutathione (GSH), which is a small-molecule antioxidant, was raised notably in IgG-deficient cells (Figure 4k). The same experiments were performed with HEp-2 and PC3 cells and identical results were obtained (Figure 4b).

Reduction of cancer-derived IgG lowers levels of intracellular ROS. It is well known that nonenzymatic and enzymatic antioxidants in vivo, including ascorbic acid, vitamin E, GSH, SOD, CAT, GR and GPx, can effectively eliminate ROS such as superoxide anion $\left(\mathrm{O}_{2}^{-}\right), \mathrm{H}_{2} \mathrm{O}_{2}$ and hydroxyl free radical $(\mathrm{OH} \cdot) \cdot{ }^{15-19}$ Our results indicated that knockdown of cancer-derived IgG significantly raised the activities of the above antioxidant enzymes. Therefore, we examined the effect of IgG on levels of intracellular $\mathrm{O}_{2}^{-}$with a dihydroethidium (DHE) assay and $\mathrm{H}_{2} \mathrm{O}_{2}$ with a dichlorofluorescein diacetate (DCFH-DA) assay. Flowcytometry and confocal microscopy analysis showed that downregulation of IgG significantly reduced DHE or DCF fluorescence intensity (Figures 5a and c). DHE and DCFH-DA assay were also performed in HEp-2 and PC3 cells under the same conditions and similar results were obtained (Figures $5 \mathrm{~b}$ and d). We also investigated the effect of IgG on endogenous $\mathrm{H}_{2} \mathrm{O}_{2}$ in cytoplasm and cell culture medium directly. Results revealed that $\mathrm{H}_{2} \mathrm{O}_{2}$ level was significantly decreased in both cytoplasm and culture medium of IgG-deficient cells (Figures $5 e$ and $\mathrm{f}$, left panel). This was in good agreement 
a



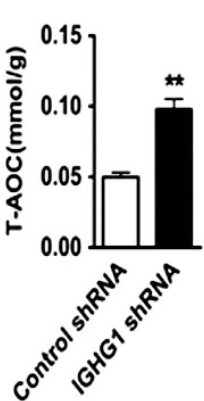

b

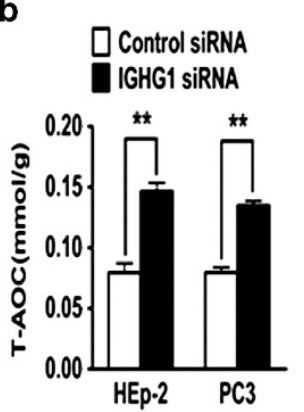

c

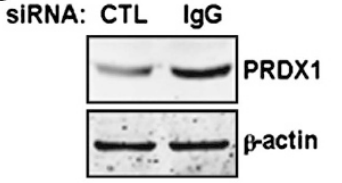

ShRNA: CTL IgG

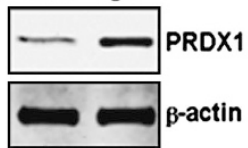

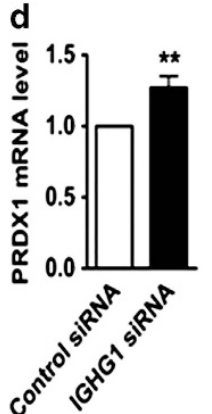

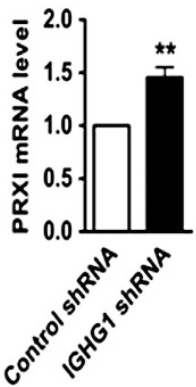

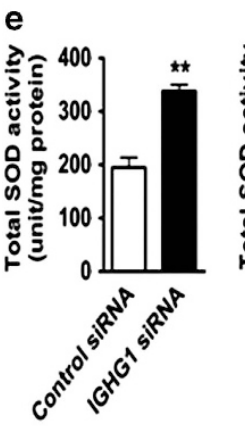
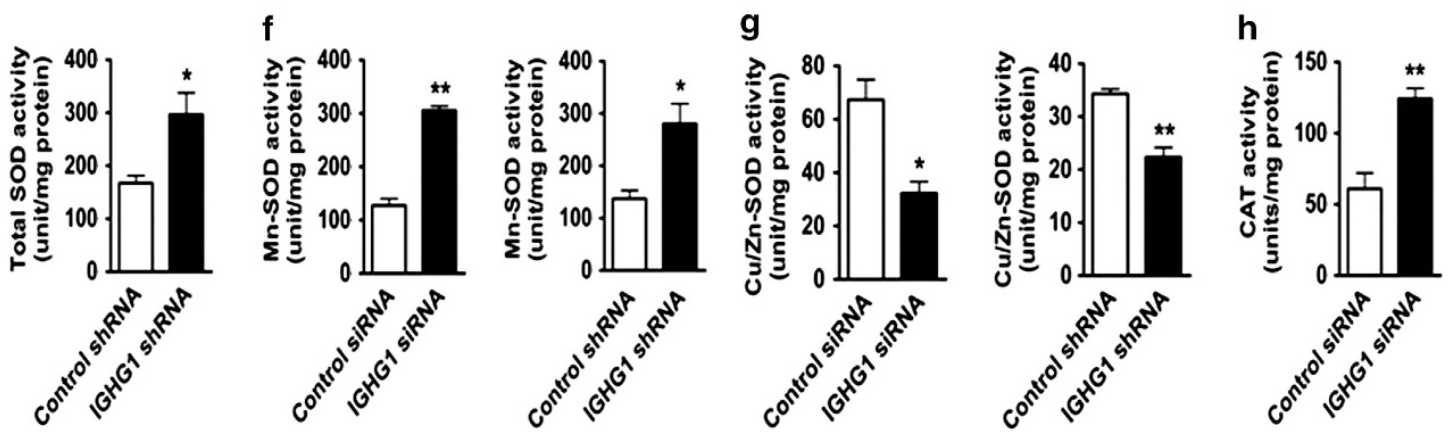

i
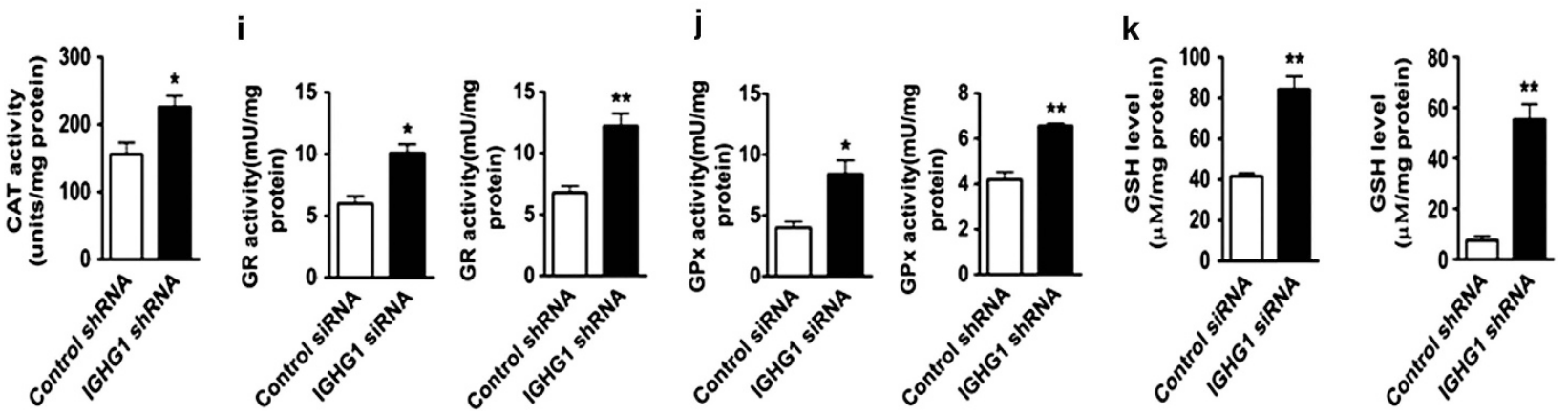

Figure 4 Downregulation of cancer-derived IgG enhanced cellular total antioxidant capacity. (a) HeLa cells were treated with IGHG1 siRNA or scrambled siRNA for $72 \mathrm{~h}$. T-AOC was measured in $593 \mathrm{~nm}$ with FRAP method with enzyme-labeling analyzer. Similar experiments were performed for HEp-2 and PC3 cells (b). After knockdown of IGHG1 in HeLa cells, the expression of PRDX1 at both protein levels (c) and mRNA levels (d) were measured. In addition, the activities of total SOD (e), Mn-SOD (f) and CuZnSOD (g) were analysed in $450 \mathrm{~nm}$ with WST-1 method by enzyme-labeling analyzer. (h) CAT activity was measured in $520 \mathrm{~nm}$ by enzyme-labeling analyzer. GR activity (i) and GPx activity (j) were measured in $340 \mathrm{~nm}$ by enzyme-labeling analyzer. (k) GSH content was detected in $412 \mathrm{~nm}$. Similar experiments were performed using HeLa cells stably expressing IGHG1 shRNA or control shRNA (a, $\mathbf{c}-\mathbf{k})$. The data of T-AOC, enzyme activities and RT-qPCR are presented as the mean \pm S.D. of three independent experiments $\left({ }^{\star} P<0.05 ;{ }^{*} P<0.01\right)$

with the results of the above DCFH experiments. Similar results were obtained using the stably transformed cells (Figures 5a, c, e, and f, right panel). In addition, the data indicated that malondialdehyde (MDA) content of IGHG1 shRNA cells was lower than that of control shRNA cells (Supplementary Figure S5a).

ROS level regulates the growth and proliferation of IgGdeficient cells via MAPK/ERK signaling pathway. It was reported that ROS at low concentration had a critical role in the growth and proliferation of cancer cells. ${ }^{20,21}$ To evaluate the role of ROS on the effect of IgG on promoting the growth and proliferation of cancer cells, HeLa cells treated with IGHG1 siRNA or scrambled siRNA were stimulated with different concentrations of CAT (a scavenger of $\mathrm{H}_{2} \mathrm{O}_{2}$ ), DMSO (a scavenger of $\mathrm{OH} \cdot$ ), NAC (a scavenger of $\mathrm{OH} \cdot$ ),
SOD (a scavenger of $\mathrm{O}_{2}^{-}$) or exogenous $\mathrm{H}_{2} \mathrm{O}_{2}$ (2 $\mathrm{uM}$ ) for $48 \mathrm{~h} .{ }^{22,23}$ Cell viability was analyzed with a cell proliferation assay. As shown in Figures 6A-D, the above ROS scavengers depressed further the growth and proliferation of IgG-deficient cells in a dose-dependent manner by decreasing the levels of intracellular ROS, whereas $\mathrm{H}_{2} \mathrm{O}_{2}$ at low concentration recovered the growth of IgG-deficient cells by increasing intracellular levels of ROS. $\mathrm{H}_{2} \mathrm{O}_{2}$ at low concentration also recovered the growth of IgG-deficient cells treated with the above ROS scavengers by increasing levels of intracellular ROS (Figure 6E). Similar results were obtained using HEp-2 cells, PC3 cells and the stably transformed cells (Figures $6 \mathrm{~F}$ and $\mathrm{G}$ and Supplementary Figure S5b). HeLa cells with the above treatments were photographed (Supplementary Figure S5c, left panel). The number of corresponding cells was shown 
(Supplementary Figure S5c, right panel). The result of statistic analysis was consistent with the MTS result, that is, ROS scavengers depressed further the growth and proliferation of IgG-deficient cells, whereas $\mathrm{H}_{2} \mathrm{O}_{2}$ at low concentration recovered the growth of IgG-deficient cells treated with or without the above ROS scavengers. In addition, results showed that siRNA-downregulated cancer-derived IgG reduced the intracellular fluorescent intensity of DCFH-DA and DHE in comparison to control siRNA. Moreover, CAT decreased further the intracellular a



C

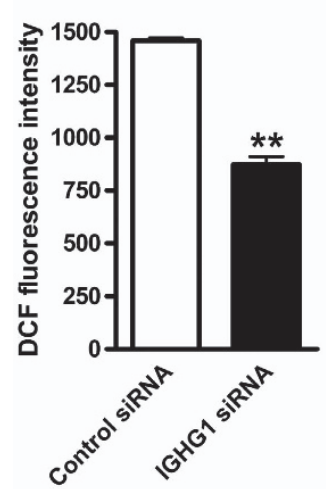

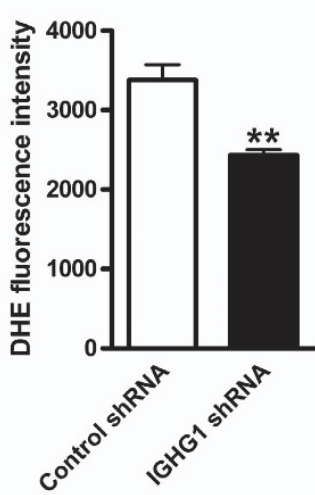

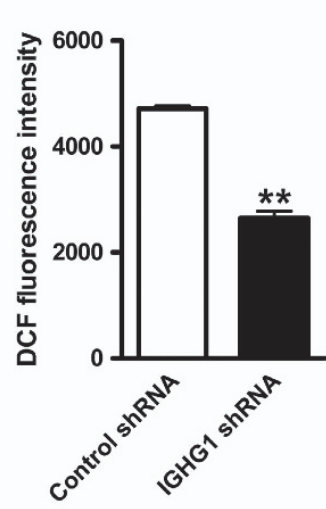

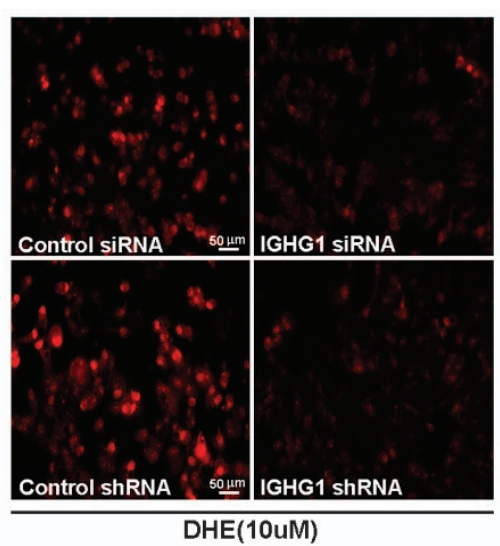

b
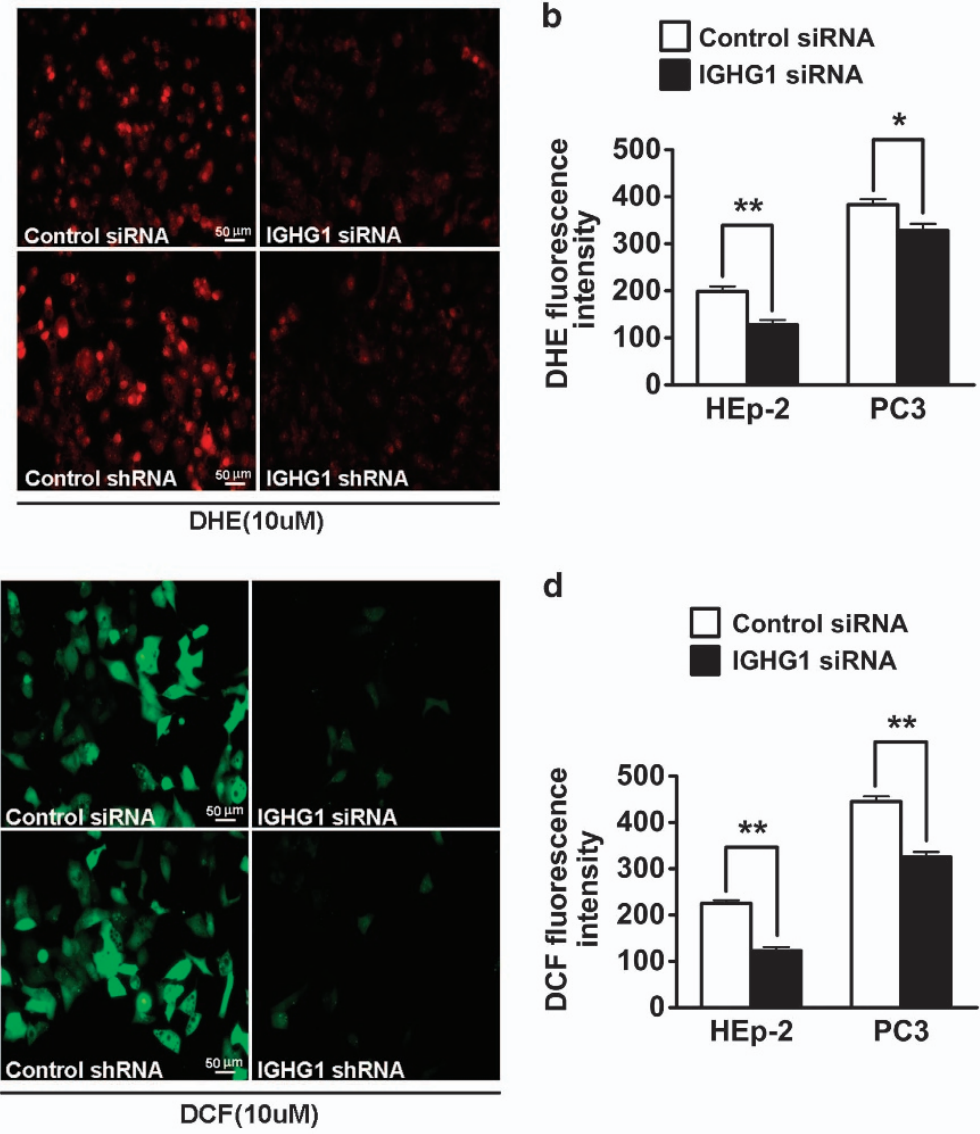

d

IGHG1 siRNA

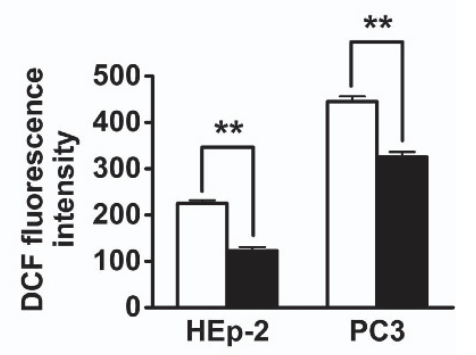

Control siRNA e

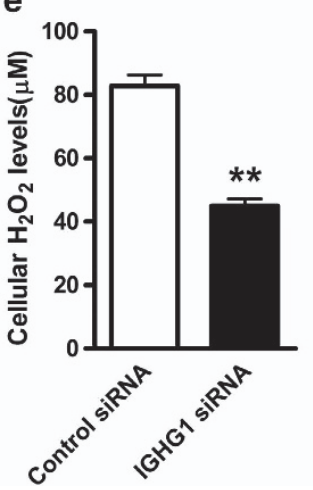

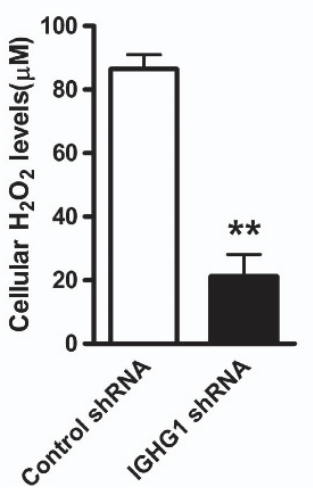

f

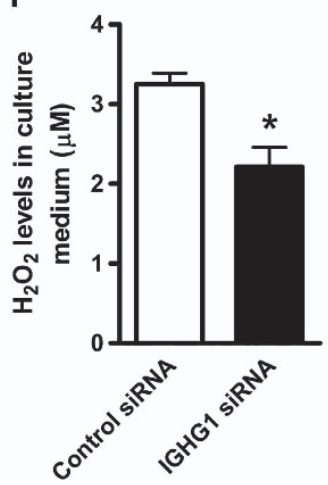

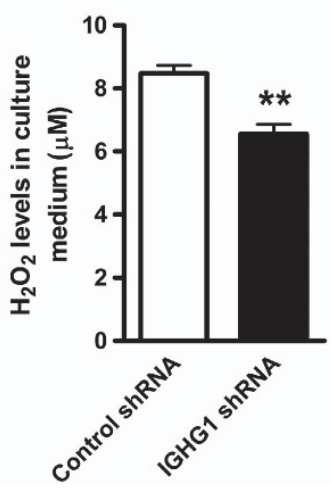

Figure 5 Downregulation of cancer-derived IgG-lowered cellular ROS level. (a) HeLa cells were treated with IGHG1 siRNA or scrambled siRNA for $72 \mathrm{~h}$. Cells were then incubated with fluorescent probe DHE at a final concentration of $10 \mu \mathrm{M}$ in high-glucose DMEM without FBS for 20 min at $37^{\circ} \mathrm{C}$, washed three times with serum-free medium and analyzed using a flow cytometry. For each analysis, 10000 events were recorded. Similarly treated cells were observed with a confocal microscope. The images are shown in the right panel. Scale bar, $50 \mu \mathrm{m}$. (b) Similar experiments were performed for HEp-2 and PC3 cells. (c) HeLa cells were transfected with IGHG1 siRNA or scrambled siRNA for $72 \mathrm{~h}$. Cells were then incubated with fluorescent probe DCFH-DA at a final concentration of $10 \mu \mathrm{M}$ in high-glucose DMEM without FBS for 20 min at $37^{\circ} \mathrm{C}$, washed three times with serum-free medium and analyzed with a flow cytometry. For each analysis, 10000 events were recorded. Similarly treated cells were observed with a confocal microscope. The images are shown in the right panel. Scale bar, $50 \mu \mathrm{m}$. (d) Intracellular ROS $\left(\mathrm{H}_{2} \mathrm{O}_{2}\right)$ level was monitored with flow cytometry with fluorescent probe DCFH-DA in HEp-2 and PC3 cells. HeLa cells were treated with IGHG1 siRNA or scrambled siRNA for $72 \mathrm{~h}$. Total lysates (e) and culture medium (f) were used to detect cellular $\mathrm{H}_{2} \mathrm{O}_{2}$ level respectively. Similar experiments were performed using HeLa cells stably expressing IGHG1 shRNA or control shRNA (a, c, e, and f). Data shown are the mean \pm S.D. of three independent experiments $\left({ }^{\star} P<0.05\right.$; $\left.{ }^{\star \star} P<0.01\right)$ 

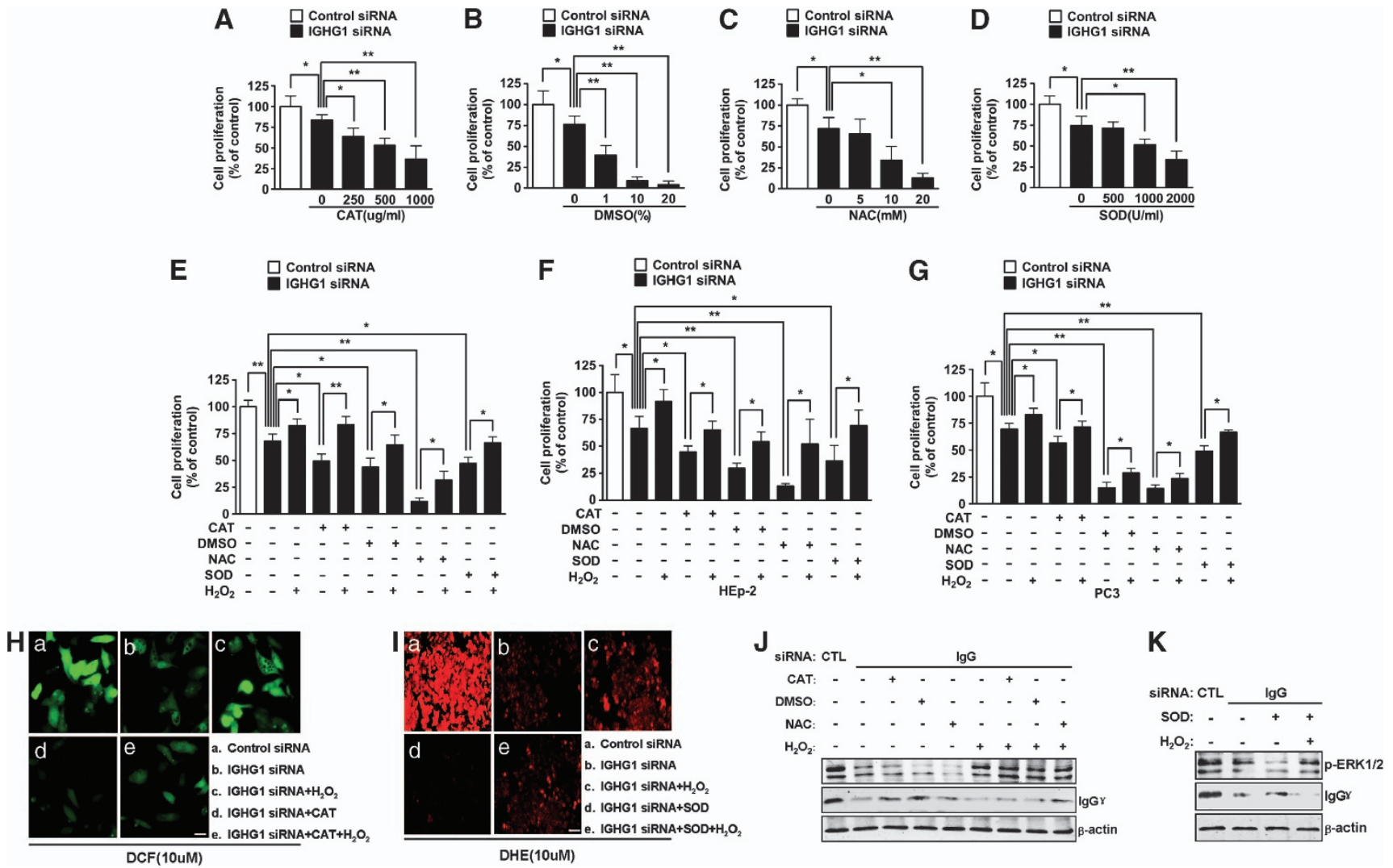

Figure 6 ROS regulated the growth and proliferation of IgG-deficient cancer cells. (A-D) HeLa cells were transfected with IGHG1 siRNA or scrambled siRNA for $72 \mathrm{~h}$, and then stimulated with different concentrations of scavengers including CAT (0,250, 500 and $1000 \mu \mathrm{g} / \mathrm{ml})$, DMSO $(0,1,10$ and 20\%), NAC $(0,5,10$ and $20 \mathrm{~mm})$, SOD $(0,500$, 1000 and $2000 \mathrm{U} / \mathrm{ml}$ ) for $48 \mathrm{~h}$. Cell viability was analyzed with a cell proliferation assay. (E) A portion of IgG-deficient cells were pretreated for $1 \mathrm{~h} \mathrm{with} \mathrm{H}_{2} \mathrm{O}_{2}(2 \mu \mathrm{M})$ and then treated with or without CAT $(500 \mu \mathrm{g} / \mathrm{ml})$, DMSO $(1 \%)$, NAC $(20 \mathrm{~mm})$ and SOD $(2000 \mathrm{U} / \mathrm{ml})$ for $48 \mathrm{~h}$. Another portion was directly stimulated with the above scavengers. Cell proliferation was determined with MTS. Results are presented as percentage of cell proliferation in comparison with the negative control. Data shown are the mean \pm S.D. of three independent experiments $\left({ }^{*} P<0.05 ;{ }^{*} P<0.01\right)$. Similar experiments were performed for HEp-2 and PC3 cells $(\mathbf{F}$ and $\mathbf{G})$. (H and I) A portion of IgG-deficient cells was pretreated for $1 \mathrm{~h}$ with $\mathrm{H}_{2} \mathrm{O}_{2}(2 \mu \mathrm{M})$ and then treated with or without CAT $(500 \mu \mathrm{g} / \mathrm{ml})$ or SOD $(2000 \mathrm{U} / \mathrm{ml})$ for $48 \mathrm{~h}$. Another portion was directly stimulated with CAT or SOD. Cells were then incubated with fluorescent probe DCFH-DA or DHE at a final concentration of $10 \mu \mathrm{M}$ in high-glucose DMEM without FBS for 20 min at $37^{\circ} \mathrm{C}$, washed three times with serum-free medium and then were observed with a confocal microscope. Scale bar, $50 \mu \mathrm{M}$. (J and K) A portion of IgG-deficient cells were pretreated for $1 \mathrm{~h}$ with $\mathrm{H}_{2} \mathrm{O}_{2}(2 \mu \mathrm{M})$ and then treated with or without CAT $(500 \mu \mathrm{g} / \mathrm{ml})$, DMSO $(1 \%)$, NAC $(20 \mathrm{~mm})$, SOD $(2000 \mathrm{U} / \mathrm{ml})$ for $48 \mathrm{~h}$. Another portion was directly stimulated with the above scavengers. Whole-cell lysates were fractionated by SDS-PAGE and blotted with anti-p-ERK and anti-lgG $\gamma$ antibodies

fluorescent intensity of DCF, and SOD decreased further that of DHE. In contrast, $\mathrm{H}_{2} \mathrm{O}_{2}$ at low concentration reversed the above effect of DCF or DHE (Figures $6 \mathrm{H}$ and I).

We also examined the signal transduction pathway induced by ROS in IgG-promoted the growth and proliferation of cancer cells. A portion of IgG-deficient HeLa cells were treated with the four ROS scavengers or $\mathrm{H}_{2} \mathrm{O}_{2}$. Another portion of IgG-deficient cells that was first treated with the four ROS scavengers were stimulated with $\mathrm{H}_{2} \mathrm{O}_{2}$ at low concentration. Results of immunoblot analysis were as follows: (1) downregulation of IgG decreased ERK phosphorylation; (2) ROS scavengers, including CAT, DMSO, NAC and SOD, decreased further ERK phosphorylation in IgG-deficient cells; (3) exogenous $\mathrm{H}_{2} \mathrm{O}_{2}$ at low concentration inhibited the reduction of ERK phosphorylation induced by knockdown of IgG or IgG together with ROS scavengers (Figures 6J and K).

IgG enhances tumor growth by inducing the production of ROS in vivo. We next tested the in vivo effects of ROS on IgG promoting tumor growth. Six BALB/c nude mice were injected with control shRNA cells (group 1) or IGHG1 shRNA cells (group 2) into the bilateral groin. In addition, another set of IGHG1 shRNA cells was also injected into the bilateral groin of six $B A L B / c$ nude mice. When the diameters of the tumors were $>0.3 \mathrm{~cm}$ after injection, $\mathrm{H}_{2} \mathrm{O}_{2}(2 \mu \mathrm{M})$ was directly injected into the tumor body (group 3 ). Tumor growth was monitored externally using vernier calipers for 8 weeks. In contrast to group 1 mice, which formed large tumors within 49 days (six out of six mice), group 2 mice formed very small tumors, while group 3 mice reversed the above phenomenon and their tumors obviously restored growth (Figures $7 \mathrm{a}$ and b). Moreover, results showed that DHE or DCF mean density of tumors tissues from group 2 mice was lower than that of group 1 mice, but that of group 3 mice was higher than that of group 2 mice. The results of MDA content, the expression of proliferating cell nuclear antigen (PCNA) and Ki67 and ERK phosphorylation were similar to those mentioned above (Figures 7d, e and Supplementary Figure S6), while the result of $\mathrm{T}-\mathrm{AOC}$ was opposite to those mentioned above (Figure 7c). 




Figure $7 \mathrm{lgG}$ induced the production of ROS to promote tumor growth in vivo. (a) Mean volumes ( $n=6$ per group) of tumors formed in the bilateral groin of BALB/c nude mice injected with controls shRNA cells or IGHG1 shRNA cells or IGHG1 shRNA cells and $\mathrm{H}_{2} \mathrm{O}_{2}$ (error bar indicates S.E.M.). (b) Gross anatomy, H\&E staining (scale bar, $20 \mu \mathrm{m}$ ), DHE and DCF staining (scale bar, $200 \mu \mathrm{m}$ ) of tumors from the above different groups of mice. DHE and DCF mean densities were analyzed in the right panel. (c) T-AOC of tumors tissues from the above different groups of mice was measured. (d) MDA contents of tumor tissues from the above different groups of mice were measured. The above data shown are the mean \pm S.D. of three independent experiments ( $\left.{ }^{*} P<0.05\right)$. (e) The tissue homogenate of tumors from the above different groups of mice were fractionated by SDS-PAGE and blotted with anti-p-ERK antibodies

ROS level and IgG expression in human cancers are closely related with their growth and proliferation. To confirm that ROS had a key role in IgG enhanced tumor growth, we analyzed ROS level in human liver cancer tissues and normal liver tissues with DHE and DCFH-DA assays (Figure 8a, left panel). The results showed that DHE or DCF mean density of liver cancer tissues was higher than that of normal liver tissues. The result of MDA content in liver cancer tissues was the same as one of DHE or DCF mean density, but different from that of T-AOC (Figure $8 \mathrm{a}$, right panel). The expressions of IgG $\gamma$, PCNA, Ki67 and PRDX1 were also examined. Immunohistochemistry results indicated that the expressions of the first three proteins were upregulated in liver cancer tissues, but the expression of the last one was downregulated, compared with normal liver tissues (Figure $8 \mathrm{a}$ and Supplementary Figure S8a). Similar results were obtained in lung cancer tissues and normal lung tissues (Figure 8b and Supplementary Figure S8b) or breast cancer tissues and normal breast tissues (Supplementary Figures S7 and 8c).

\section{Discussion}

In this study, we first confirmed the expression of IgG in a number of cancer cell lines. We then explored the roles of cancer-derived IgG in cell growth and proliferation and established that downregulation of IgG suppressed the growth and proliferation of cancer cells and arrested cell cycle
(S phase). In vivo, nude mouse tumorigenicity assay was carried out to confirm the above results. To elucidate its mechanism, we performed a co-immunoprecipitation assay and identified 27 cancer-derived IgG-associated proteins. Functional annotation identified RACK1, RAN and PRDX1 involved in cancer cell growth and oxidative stress, which prompted us to investigate the mechanism of action of cancerderived IgG in the above phenomena. Further experiments revealed that cancer-derived IgG enhanced cell growth and proliferation via inducing the production of ROS at low level in vitro and in vivo. These findings demonstrate that ROS have a pivotal role in IgG-induced growth and proliferation of cancer cells. The proposed mechanism is illustrated in Figure 9.

Among the 27 candidate molecules, half of them are intimately correlated with cell growth or proliferation. For example, a ribosomal protein (RP) family, including RPL10L, RPL13, RPL13a, RPL15 and RPL18, has essential roles in protein synthesis and macromolecule metabolism. Interaction with these proteins suggests that cancer-derived IgG may promote cell growth and proliferation through regulating proteins related to metabolism or ribosomal protein family and activating the proliferative signaling pathway. In this study, IgG interacted with three proteins associated with cell growth, that is, RACK1, RAN and PRDX1, and these three proteins also interacted with each other. Therefore, the above four proteins are likely to form a macro-complex. It has been shown that nonenzymatic and enzymatic antioxidants, including ascorbic acid, vitamin E, GSH, SOD, CAT, GR and 
a

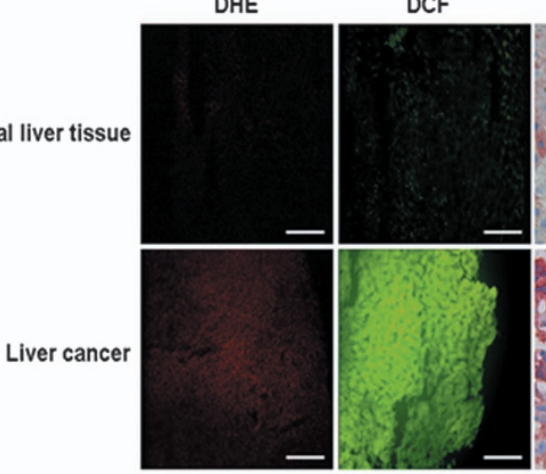

$\square$ Normal liver tissue 目 Liver cancer

DCF

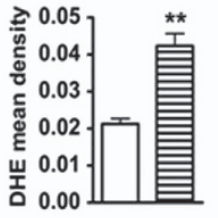

IgGY



PCNA

Ki67

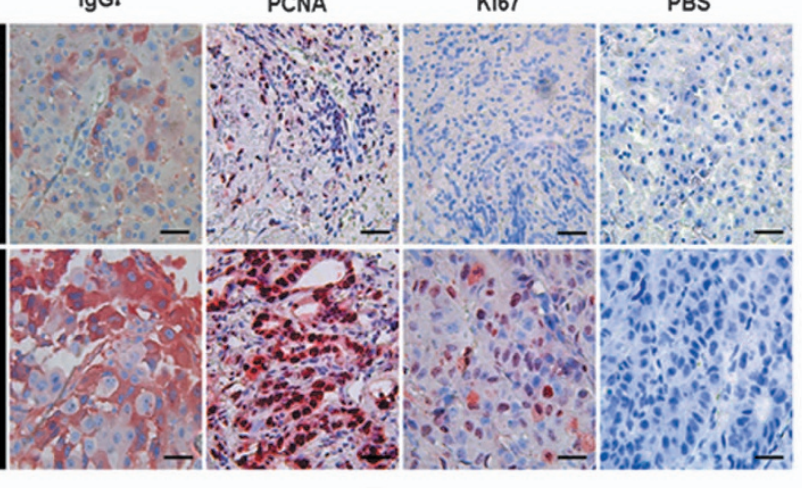

$\square$ Normal liver tissue

$\square$ Normal liver tissue

目 Liver cancer

目 Liver cancer
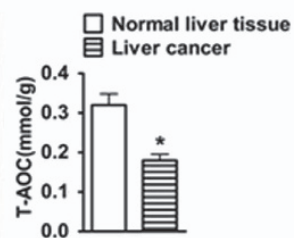

$\square$ Normal liver tissue

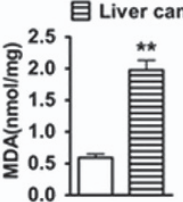

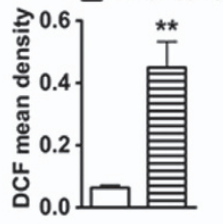

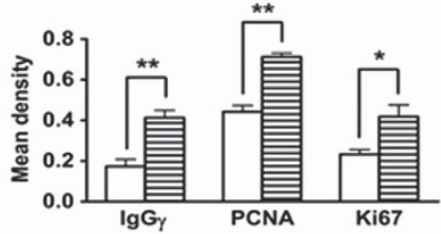

b
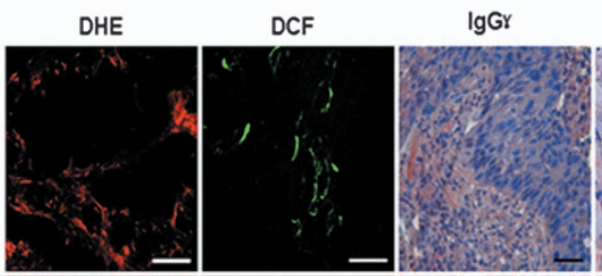

PCNA

Ki67
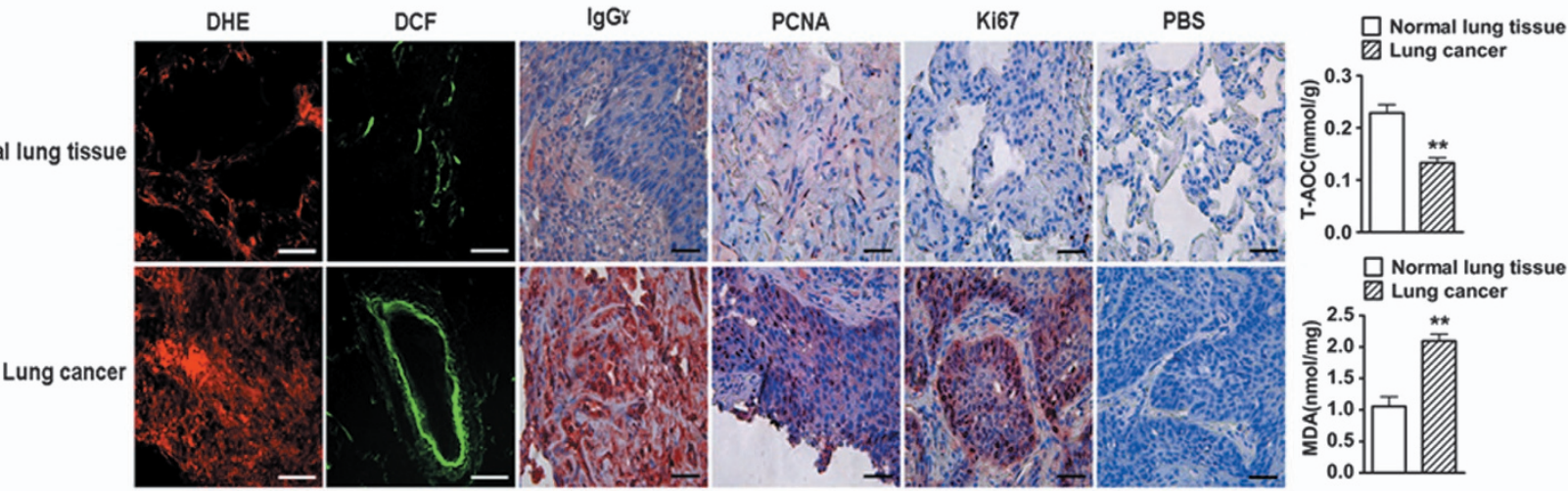

$\square$ Normal lung tissue

$\square$ Lung cancer
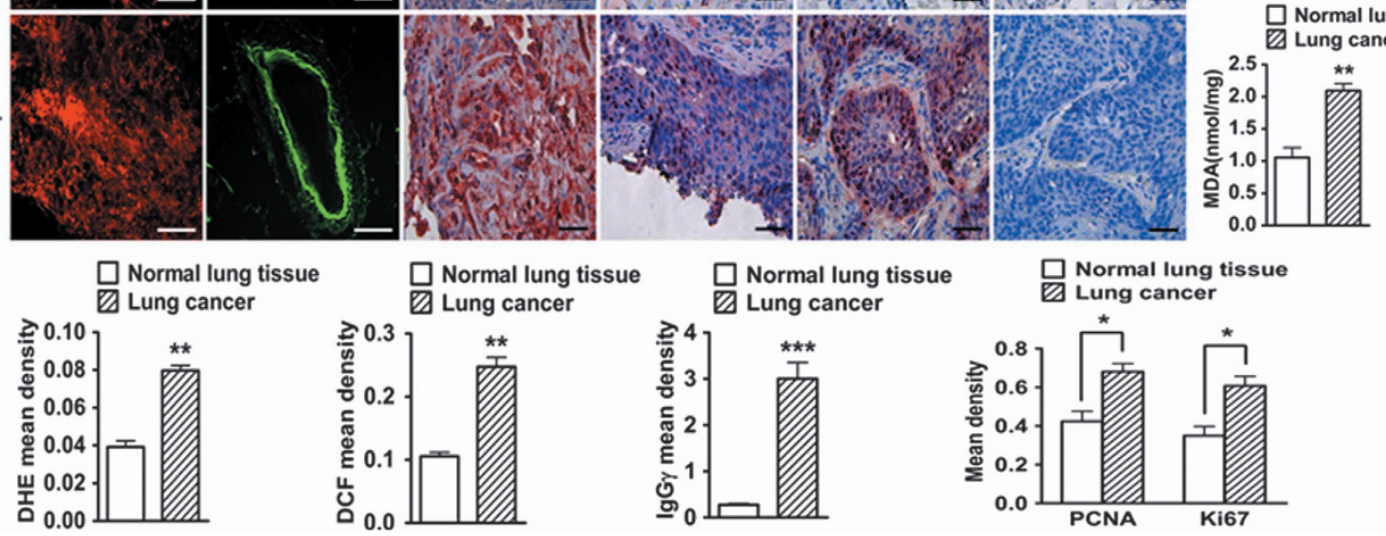

Figure 8 The close relationship between ROS level and lgG expression in human cancer and their proliferation. (a) The analytic comparison of ROS level (scale bar, $200 \mu \mathrm{m}$ ), IgG $\gamma$, PCNA and Ki67 expression (scale bar, $20 \mu \mathrm{m}$ ) in liver cancer tissues and normal liver tissues. T-AOC and MDA contents of the above tissues were measured and presented in the right panel. Data shown are the mean \pm S.D. of three independent experiments $\left({ }^{\star} P<0.05 ;{ }^{* \star} P<0.01 ;{ }^{* \star *} P<0.001\right)$. Similar experiments were performed using lung cancer tissues and normal lung tissues (b) and breast cancer tissues and normal breast tissues (Supplementary Figure S7)

GPx, can efficiently safeguard against the accumulation of intercellular ROS such as $\mathrm{O}_{2}^{-}, \mathrm{H}_{2} \mathrm{O}_{2}$ and $\mathrm{OH} \cdot{ }^{15-19}$ In our study, knockdown of IgG increased cellular total antioxidant capacity including activities of some antioxidant enzymes (total SOD, Mn-SOD, CuZn-SOD, CAT, GR, GPx), the expression level of PRDX1 and small molecular antioxidant (GSH) content. In contrast, the levels of corresponding target ROS molecules including $\mathrm{O}_{2}^{-}$and $\mathrm{H}_{2} \mathrm{O}_{2}$ decreased significantly, suggesting that cancer-derived IgG has a role in regulating cellular antioxidant response.

ROS is a double-edged sword. The harmful effects of ROS appear at a high level. Over production of ROS causes cellular damage, dysfunction, growth inhibition, and so on. ${ }^{24-27}$ However, the beneficial effects of ROS occur at low or moderate level and involve physiological roles in cellular responses, signaling and regulation. ${ }^{28-30}$ It should be pointed out that the low or moderate level of ROS production is the level at which ROS participates in cellular normal physiological functions and provides essential protective mechanisms. The high level of ROS production is the level at which ROS will lead to deleterious effects such as membrane lipid peroxidation, protein oxidation, DNA damage and disturbance of cellular redox equivalents, which induce cell death, apoptosis and senescence. Therefore, the cutoff values to define 

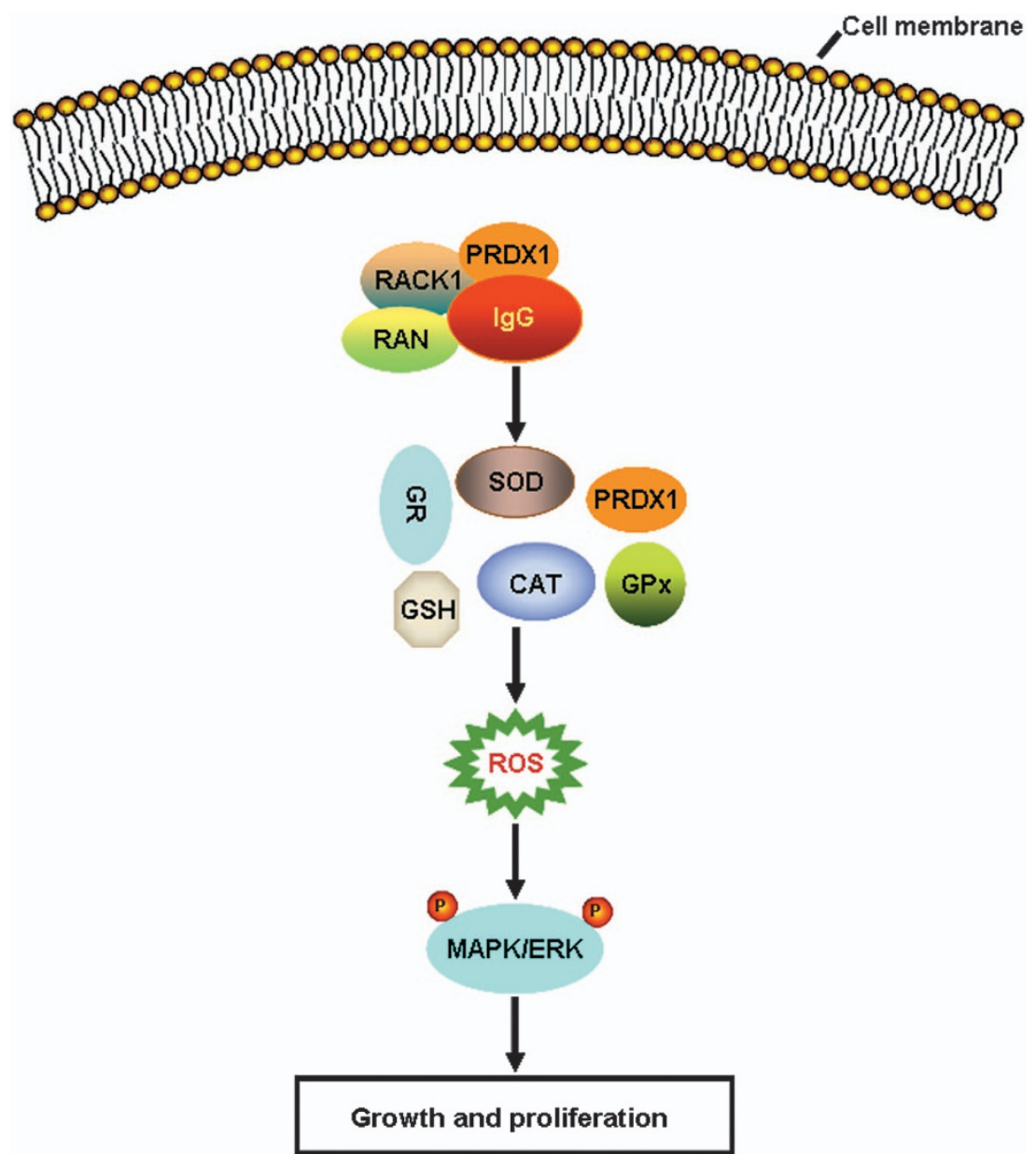

Figure 9 A schematic model of cancer-derived lgG to enhance cell growth and proliferation through inducing the production of a low level of ROS. Based on our findings, we propose the following mechanism. The interaction between IgG and RACK1, RAN and PRDX1 prompted us to explore the mechanism of action of cancer-derived lgG in cell growth and oxidative stress. Cancer-derived IgG decreased cellular total antioxidant capacity including activities of some antioxidant enzymes (SOD, CAT, GR and GPX), the expression level of PRDX1 and GSH content. The decreased total antioxidant capacity in turn induces production of a low level of intracellular ROS that activates MAPK/ ERK signaling pathway to enhance growth and proliferation of cancer cells

low-moderate-high levels of ROS production is based on whether or not ROS does damage to normal physiological function of cells and the degree of free radical damage. In fact, there are different cutoff values to define low-moderate-high levels of ROS production in different cancer cells. In this study, according to the experimental results, the level or concentration of $\mathrm{H}_{2} \mathrm{O}_{2}$ less than or equal to $2 \mu \mathrm{M}$ is defined as low level, $2-1000 \mu \mathrm{M}$ of $\mathrm{H}_{2} \mathrm{O}_{2}$ is defined as moderate level and equal to or greater than $1000 \mu \mathrm{M}$ is defined as high level. Studies have shown that cancer cells exhibiting an accelerated metabolism demand a relatively high ROS level to maintain their high proliferative rate. ${ }^{31}$ ROS can promote many aspects of tumor development and progression that can be classified into the following four biological processes: (1) cellular proliferation, for example, ligand-independent receptor tyrosine kinase (RTK) activation and ERK1/2 activation; (2) evasion of apoptosis, for example, nuclear factor kappa B (NF- $k \mathrm{~B})$, Src and phosphatidylinositol-3 kinase (PI3K)/Akt activation; (3) angiogenesis, for example, the release of vascular endothelial growth factor (VEGF) and angiopoietin and (4) tissue metastasis and invasion, for example, metalloproteinase secretion into the extracellular matrix, and the interaction between Rho and Rac. ${ }^{32,33}$ Our results indicated that knockdown of cancer-derived IgG lowered cellular ROS levels via increasing the activities of antioxidant enzymes such as SOD, CAT, GR and GPx, the expression level of PRDX1 and GSH content. Therefore, under normal physiological conditions, IgG induces cancer cells to produce ROS at low level but not at moderate or high level through inhibiting the above antioxidant system, as the latter two are not beneficial to cancer cell growth. Previous studies have demonstrated that ROS at low level promoted cancer cells growth and proliferation. ${ }^{34-36}$ In our study, ROS scavengers, including CAT, DMSO, NAC and SOD, further depressed the growth of IgG-deficient cells to different degrees by decreasing levels of intracellular ROS, whereas exogenous $\mathrm{H}_{2} \mathrm{O}_{2}$ at low concentration reversed the depression of IgG-deficient cells by increasing the levels of intracellular ROS. Similar results were obtained in the ROS animal model and human tissues. The above findings establish that ROS acts as a key mediator in IgG-induced growth and proliferation of cancer cells. 
Signal transduction mechanism of cancer-derived IgG has not been reported previously. Our study found that downregulation of $\mathrm{IgG}$ decreased ERK phosphorylation. ROS scavengers further decreased ERK phosphorylation in IgG-deficient cells. In contrast, exogenous $\mathrm{H}_{2} \mathrm{O}_{2}$ at low concentration recovered the reduction of ERK phosphorylation induced by knockdown of not only IgG but also IgG together with ROS scavengers. Similar results were obtained in the ROS animal model. MAPK/ERK pathway is an important signal transduction pathway and has a close relation with cell growth and differentiation. ${ }^{37-39}$ Our findings strongly suggest that cancer-derived IgG activates MAPK/ ERK signaling pathway, leading to cell proliferation through inducing the production of intracellular ROS at low level.

In summary, cancer-derived IgG induced the production of intracellular ROS at low level via attenuating cellular total antioxidant capacity, which in turn promoted the growth and proliferation of cancer cell through activating MAPK/ERK signaling pathway. The proposed mechanism provides a new perspective to investigate functions of cancer-derived IgG and new clues for tumor biology. Further studies should be carried out to investigate details of this mechanism and their significance in cancer therapy.

\section{Materials and Methods}

Cell culture and human tissue specimens. The human cervical cancer cell line HeLa, laryngeal cancer cell line HEp-2, pancreatic cancer cell line PC3, liver cancer cell line Hep3B, breast ductal cancer cell line BT549 and Burkitt lymphoma cell line Raji were obtained from the ATCC. The above cell lines were cultured in Dulbecco's Modified Eagle's Medium (DMEM, Invitrogen, Carlsbad, CA, USA) with $10 \%$ FBS (Hyclone/Thermo Fisher Scientific Inc., Waltham, MA, USA) at $37^{\circ} \mathrm{C}$ in a humidified atmosphere with $5 \% \mathrm{CO} 2$. The stably transformed HeLa cells were selected with $800 \mu \mathrm{g} / \mathrm{ml}$ of antibiotic G-418 (BBI, Toronto, ON, Canada). Human liver cancer tissues, lung cancer tissues, primary breast cancer tissues, cervical cancer tissues and their normal tissues surgically removed and snap-frozen in liquid nitrogen were obtained from Cancer Hospital of Shantou University Medical College. The study was approved by the Ethical Committee of Shantou University Medical College.

Immunoprecipitation and western blot analysis. Whole-cell lysates of HeLa cells were incubated with monoclonal mouse anti-human IgG antibody ( $\gamma$ chain-specific) (Sigma, St. Louis, MO, USA) at $4^{\circ} \mathrm{C}$ overnight, and then precipitated with 30 ul protein $\mathrm{G}$ agarose (Santa Cruz Biotechnology, Santa Cruz, CA, USA) for $1 \mathrm{~h}$. Immunocomplexes were washed and boiled, separated by SDSPAGE and then transferred to nitrocellulose membranes. Membranes were blocked with $5 \%$ bovine serum albumin in Tris-buffered saline containing $0.2-0.4 \%$ Tween-20 (TBST), and incubated with primary antibodies (Supplementary Table S3) at $4{ }^{\circ} \mathrm{C}$ overnight. Western blotting was analyzed with Alex680- and IR700conjugated secondary antibodies in a two-color LI-COR Odyssey Imaging System (LI-COR Biosciences, Lincoln, NE, USA).

Protein identification with mass spectrometry. Silver-stained SDS-PAGE gels were photographed, and the bands that differentiated between the experimental group with IgG antibodies and the control group with normal IgG were cut out. Protein samples were identified as previously described. ${ }^{40}$

Immunohistochemistry and immunofluorescence. Immunohistochemistry was performed on paraformaldehyde-fixed samples as previously described. ${ }^{7}$ Immunofluorescence was performed as previously described. ${ }^{5}$ Confocal microscopic images were obtained with an Olympus confocal imaging system (Olympus, Tokyo, Japan).

RNA purification, RT-PCR and RT-qPCR. Total RNA was isolated from the cells using Trizol reagent (Invitrogen, Camarillo, CA, USA) and treated with RNase Free DNase (Invitrogen) to remove genomic DNA. Reverse transcription of total RNA was performed using PrimeScript RT reagent Kit Perfect Real Time (Invitrogen). Conventional, nested or semi-nested PCR was performed and the primers used in this study were listed in Supplementary Table S4. RT-qPCR analysis was performed using the ABI7300 (Applied Biosystems, Foster City, CA, USA). The primers were shown in Supplementary Table S4.

RNA interference. siRNAs were transfected into HeLa, PC3 and HEp-2 cells with X-tremeGENE siRNA Transfection Reagent (Roche Applied Science, Indianapolis, IN, USA). Cells were further analyzed $72 \mathrm{~h}$ after transfection. IGHG1 siRNA sequence was listed in Supplementary Table S5.

Short tandem repeat analysis. Short tandem repeat analysis of the HeLa, HEp-2 and PC3 cell lines was performed by Beijing Microread Gene Technology Co., Ltd (Beijing, China) and Beijing JianLian Genes Technology Co., Ltd (Beijing, China).

Cell cycle and ROS analyses with flow cytometry. After siRNAmediated knockdown of IGHG1, HeLa cells were fixed with $70 \%$ ethanol and kept at $4{ }^{\circ} \mathrm{C}$ overnight. After centrifugation, cell pellets were stained in PBS containing propidium iodide for $30 \mathrm{~min}$. Distribution of the cell cycle was then analyzed using a FACS Ariall flow cytometer (Becton Dickinson, Franklin Lakes, NJ, USA). HeLa cells were washed and incubated with $10 \mu \mathrm{M}$ DCFH-DA or DHE for $30 \mathrm{~min}$ at $37^{\circ} \mathrm{C}$. Fluorescence was monitored using a FACS Ariall flow cytometer.

MTS assay. HeLa cells, PC3 cells and HEp-2 cells ( $\sim 5000$ per well) were transfected with IGHG1 siRNA or scrambled siRNA. After $72 \mathrm{~h}$, cell viability was analyzed with the CellTiter 96 Aqueous One Solution Cell Proliferation Assay (Promega, Madison, WI, USA).

Analysis of tumor growth. Six female BALB/c nude mice were injected with control shRNA cells (group 1), IGHG1 shRNA cells (group 2) and IGHG1 shRNA cells (group 3). Cells $\left(5 \times 10^{7}\right.$ in a volume of $200 \mu$ normal saline) were injected subcutaneously into the bilateral groin. Tumor growth was monitored externally using vernier calipers for 8 weeks. When the diameters of tumor were $>.3 \mathrm{~cm}$ after injection, $\mathrm{H}_{2} \mathrm{O}_{2}(2 \mu \mathrm{M})$ was directly injected into the tumor body of group 3 mice for 7 weeks. At 8 weeks after injection, all mice were killed after the photograph was taken. Their tumors were removed and partly fixed in $10 \%$ formalin, the other stored at $-70^{\circ} \mathrm{C}$

Measurement of T-AOC, antioxidant enzyme activities, GSH content and $\mathrm{H}_{2} \mathrm{O}_{2}$ level. The total antioxidant capacity was determined using a T-AOC Assay Kit with ferric reducing ability of plasma (FRAP) method (S0116, Beyotime, Shanghai, China) as previously described. ${ }^{41}$ The activities of total SOD, CuZn/Mn-SOD, CAT, GR and GPx in the samples were determined using a Total SOD Assay Kit with WST (S0102, Beyotime), a CuZn/Mn-SOD Assay Kit with WST (S0105, Beyotime), a CAT Assay Kit (S0051, Beyotime), a GR Assay Kit (S0055, Beyotime) and a Total GPx Assay Kit (S0058, Beyotime) as previously described. ${ }^{42-44}$ The GSH content was determined using GSH and GSSG Assay Kit (S0053, Beyotime) as previously described. ${ }^{45} \mathrm{The}_{2} \mathrm{O}_{2}$ content was determined using a $\mathrm{H}_{2} \mathrm{O}_{2}$ Assay Kit (S0038, Beyotime) as previously described. $^{46}$

Statistical analysis. SPSS software (version 16.0; SPSS, Inc., Chicago, IL, USA) was used for statistical analysis. All experiments were repeated at least three times. The data were expressed as the mean \pm S.D. and compared with independent-samples $t$-test. The significant level was set at $P<0.05$.

\section{Conflict of Interest}

The authors declare no conflict of interest.

Acknowledgements. We are grateful for the support from the Center for Neuroscience, Shantou University Medical College for the utilization of the laser confocal microscopy, and to Professor Liyun Shi (Hangzhou Normal University), Professor Haiyun Xu (Shantou University Medical College) and Drs Xiangwei Gao, Saisai Wei (Zhejiang University School of Medicine) for critical review of the manuscript. This work was supported by grants from National Natural Science Foundation of China to JG (no. 30971150). The funders had no role in study design, data collection and analysis, decision to publish or preparation of the manuscript. 
1. Qiu X, Zhu X, Zhang L, Mao Y, Zhang J, Hao P et al. Human epithelial cancers secrete immunoglobulin $g$ with unidentified specificity to promote growth and survival of tumor cells. Cancer Res 2003; 63: 6488-6495.

2. Zhang S, Mao Y, Huang J, Ma T, Zhang L, Zhu X et al. Immunoglobulin gene locus events in epithelial cells of lactating mouse mammary glands. Cell Mol Life Sci 2010; 67: 985-994.

3. Ma C, Wang Y, Zhang G, Chen Z, Qiu Y, Li J et al. IgG expression and its potential role in primary and metastatic breast cancers. Curr Mol Med 2013; 13: 429-437.

4. Chen Z, Qiu X, Gu J. Immunoglobulin expression in non-lymphoid lineage and neoplastic cells. Am J Pathol 2009; 174: 1139-1148.

5. Niu N, Zhang J, Huang T, Sun Y, Chen Z, Yi W et al. IgG expression in human colorectal cancer and its relationship to cancer cell behaviors. PLOS One 2012; 7: e47362.

6. Liu Y, Chen Z, Niu N, Chang Q, Deng R, Gu J et al. IgG gene expression and its possible significance in prostate cancers. Prostate 2012; 72: 690-701.

7. Qiu Y, Korteweg C, Chen Z, Li J, Luo J, Gu J et al. Immunoglobulin G expression and its colocalization with complement proteins in papillary thyroid cancer. Mod Pathol 2012; 25: $36-45$.

8. Chen Z, Huang X, Ye J, Pan P, Cao Q, Yang B et al. Immunoglobulin G is present in a wide variety of soft tissue tumors and correlates well with proliferation markers and tumor grades. Cancer 2010; 116: 1953-1963.

9. Zhao Y, Liu Y, Chen Z, Korteweg C, Gu J. Immunoglobulin G (IgG) expression in human umbilical endothelial cells. J Histochem Cytochem 2011; 59: 474-488.

10. Huang J, Zhang L, Ma T, Zhang P, Qiu X. Expression of immunoglobulin gene with classicalV-(D)-J rearrangement in mouse testis and epididymis. J Histochem Cytochem 2009; 57: 339-349.

11. Niu N, Zhang J, Guo Y, Zhao Y, Korteweg C, Gu J. Expression and distribution of immunoglobulin $G$ and its receptors in the human nervous system. Int J Biochem Cell Biol 2011; 43: 556-563.

12. Huang J, Sun $X$, Mao $Y$, Zhu $X$, Zhang $P$, Zhang $L$ et al. Expression of immunoglobulin gene with classical V-(D)-J rearrangement in mouse brain neurons. Int J Biochem Cell Biol 2008; 40: 1604-1615.

13. Niu N, Zhang J, Sun Y, Wang S, Sun Y, Korteweg $C$ et al. Expression and distribution of immunoglobulin $\mathrm{G}$ and its receptors in an immune privileged site: the eye. Cell Mol Life Sci 2011; 68: 2481-2492.

14. Li M, Zheng H, Duan Z, Liu H, Hu D, Bode A et al. Promotion of cell proliferation and inhibition of ADCC by cancerous immunoglobulin expressed in cancer cell lines. Cell $\mathrm{Mol}$ Immunol 2012; 9: 54-61.

15. Hassan HM. Biosynthesis and regulation of superoxide dismutases. Free Radic Biol Med 1988; 5: 377-385

16. Matés JM, Sánchez-Jiménez F. Antioxidant enzymes and their implications in pathophysiologic processes. Front Biosci 1999; 4: 339-345.

17. Matés JM, Pérez-Gómez $C$, Núñez de Castro I. Antioxidant enzymes and human diseases. Clin Biochem 1999; 32: 595-603.

18. Matés JM. Effects of antioxidant enzymes in the molecular control of reactive oxygen species toxicology. Toxicology 2000; 153: 83-104.

19. Geslin C, Llanos J, Prieur D, Jeanthon C. The manganese and iron superoxide dismutases protect Escherichia coli from heavy metal toxicity. Res Microbiol 2001; 152: 901-905.

20. Tang $H$, Qin $Y$, Li J, Gong $X$. The scavenging of superoxide radicals promotes apoptosis induced by a novel cell-permeable fusion protein, sTRAIL: FeSOD, in tumor necrosis factor-related apoptosis-inducing ligand-resistant leukemia cells. BMC Biol 2011; 9: 18.

21. Panieri E, Gogvadze V, Norberg E, Venkatesh R, Orrenius S, Zhivotovsky B. Reactive oxygen species generated in different compartments induce cell death, survival, or senescence. Free Radical Biol Med 2013; 57: 176-187.

22. Zhang Q, Zeng X, Guo J, Wang X. Effects of homocysteine on murine splenic B lymphocyte proliferation and its signal transduction mechanism. Cardiovasc Res 2001; 52: 328-336.

23. Zhang $Q$, Zeng X, Guo J, Wang X. Oxidant stress mechanism of homocysteine potentiating Con A-induced proliferation in murine splenic T lymphocytes. Cardiovasc Res 2002; 53 1035-1042.
24. Devasagayam TP, Tilak JC, Boloor KK, Sane KS, Ghaskadbi SS, Lele RD. Free radicals and antioxidants in human health: current status and future prospects. J Assoc Physicians India 2004; 52: 794-804.

25. M Valko D. Free radicals and antioxidants in normal physiological functions and human disease. Int J Biochem Cell Biol 2007; 39: 44-84.

26. Fang YZ, Yang S, Wu G. Free radicals, antioxidants, and nutrition. Nutrition 2002; 18: 872-879.

27. Lander HM. An essential role for free radicals and derived species in signal transduction. FASEB J 1997; 11: 118-124.

28. Barbieri E, Sestili P. Reactive oxygen species in skeletal muscle signaling. J Signal Transduct 2012; 2012: 982794.

29. Veal EA, Day AM, Morgan BA. Hydrogen peroxide sensing and signaling. Mol Cell 2007; 26: $1-14$.

30. Schreck R, Baeuerle PA. A role for oxygen radicals as second messengers. Trends Cell Biol 1991; 1: 39-42.

31. Sosa V, Moliné T, Somoza R, Paciucci R, Kondoh H, LLeonart ME. Oxidative stress and cancer: an overview. Ageing Res Rev 2012; 12: 376-390.

32. Sundaresan M, Yu ZX, Ferrans VJ, Irani K, Finkel T. Requiremen for generation of $\mathrm{H} 2 \mathrm{O} 2$ for platelet-derived growth factor signal transduction. Science 1995; 270: 296-299.

33. Ushio-Fukai M, Nakamura Y. Reactive oxygen species and angiogenesis: NADPH oxidase as target for cancer therapy. Cancer Lett 2008; 266: 37-52.

34. Wiemer EA. Stressed tumor cell, chemosensitized cancer. Nat Med 2011; 17: 1552-1554.

35. Matsuzawa A, Ichijo $\mathrm{H}$. Redox scrambled of cell fate by MAP kinase: physiological roles of ASK1-MAP kinase pathway in stress signaling. Biochim Biophys Acta 2011; 1780: 1325-1336.

36. Guyton KZ, Liu Y, Gorospe M, Xu Q, Holbrook NJ. Activation of mitogen-activated protein kinase by $\mathrm{H}_{2} \mathrm{O}_{2}$ : role in cell survival following oxidant injury. J Biol Chem 1996; 271 : 4138-4142.

37. Mielgo A, Seguin L, Huang M, Camargo MF, Anand S, Franovic A et al. A MEK-independent role for CRAF in mitosis and tumor progression. Nat Med 2011; 17: 1641-1645.

38. Dreesen O, Brivanlou AH. Signaling pathways in cancer and embryonic stem cells. Stem Cell Rev 2007; 3: 7-17.

39. Gao J, Zhao Y, Lv Y, Chen Y, Wei B, Tian J et al. Mirk/Dyrk1B mediates G0/G1 to S phase cell cycle progression and cell survival involving MAPK/ERK signaling in human cancer cells. Cancer Cell Int 2013; 13: 2.

40. Wei S, Gao X, Du J, Su J, Xu Z. Angiogenin enhances cell migration by regulating stress fiber assembly and focal adhesion dynamics. PLoS One 2011; 6: e28797.

41. Zhou Y, Yuan J, Wu J, Han X. The toxic effects of microcystin-LR on rat spermatogonia in vitro. Toxicol Lett 2012; 212: 48-56.

42. Peskin AV, Winterbourn CC. A microtiter plate assay for superoxide dismutase using a water-soluble tetrazolium salt (WST-1). Clin Chim Acta 2000; 293: 157-166.

43. He Z, Sun X, Mei G, Yu S, Li N. Nonclassical secretion of human catalase on the surface of $\mathrm{CHO}$ cells is more efficient than classical secretion. Cell Biol Int 2008; 32: 367-373.

44. Xiao-Long W, Chuan-Ping Y, Kai X, Ou-Jv Q. Selenoprotein W depletion in vitro might indicate that its main function is not as an antioxidantive enzyme. Biochemistry (Moscow) 2010; 75: 201-207.

45. Jia JH, Wang Y, Cao YB, Gao PH, Jia XM, Ma ZP et al. CalPF7817 is involved in the regulation of redox homeostasis in Candida albicans. Biochem Biophys Res Commun 2007; 359: 163-167.

46. Dai X, Sun Y, Gao Z, Jiang Z. Copper enhances amyloid-beta peptide neurotoxicity and non beta-aggregation: a series of experiments conducted upon copper-bound and copperfree amyloid-beta peptide. J Mol Neurosci 2010; 41: 66-73.

(c) (i) (s) $\Theta$ Cell Death and Disease is an open-access journal published by Nature Publishing Group. This work is licensed under a Creative Commons Attribution-NonCommercialNoDerivs 3.0 Unported License. To view a copy of this license, visit http://creativecommons.org/licenses/by-nc-nd/3.0/

Supplementary Information accompanies this paper on Cell Death and Disease website (http://www.nature.com/cddis) 